\title{
Research of Surrogate Measure for Freeway Crashes Based on Tire Skid Marks
}

\author{
Yan Ma $\mathbb{D},{ }^{1}$ Wenjing Huang, ${ }^{1}$ Zong Tian $\mathbb{D}^{2},{ }^{2}$ Donghong Li, ${ }^{1}$ Hongzhou Cai, ${ }^{1}$ and Jie Su ${ }^{1}$ \\ ${ }^{1}$ School of Civil Engineering, Tianjin Chengjian University, 26 Jinjing Road, Tianjin 300384, China \\ ${ }^{2}$ Center for Advanced Transportation Education and Research, University of Nevada (Reno), 1664 N Virginia Street, Reno, \\ NV 89557, USA \\ Correspondence should be addressed to Zong Tian; zongt@unr.edu
}

Received 13 November 2020; Revised 1 August 2021; Accepted 27 August 2021; Published 18 October 2021

Academic Editor: Neng-Chao Lyu

Copyright (c) 2021 Yan Ma et al. This is an open access article distributed under the Creative Commons Attribution License, which permits unrestricted use, distribution, and reproduction in any medium, provided the original work is properly cited.

\begin{abstract}
Traditional approaches to evaluating and predicting safety issues in traffic systems are via crash records. However, considering the characteristics of scarcity, inconsistency, inaccuracy, and incompleteness of crash records, conclusions and recommendations drawn purely based on crashes have limitations. Tire skid marks are considered an indication of some safety hazards, and it could have good potential to be used as surrogates for crashes. By collecting and analyzing the data based on selected arterial and freeway segments in the Reno-Sparks area in northern Nevada, a methodology was developed to categorize different tire skid marks. Sliding window and linear regression techniques were applied to determine any correlation between tire skid marks and crashes. The analyses indicated that there was a relatively strong linear correlation between skid marks and crashes on freeway segments.
\end{abstract}

\section{Introduction}

The current practice of traffic safety programs primarily relies on crash data, such as crash frequency, crash rate, and crash severity, for making roadway safety improvement decisions. Such an approach is considered a passive or reactive approach because corrective action takes place only after crashes have occurred. Additionally, there are some limitations of using crash data, including randomness, underreporting, subjectivism, and long observation periods [1]. These limitations of crash data may hinder comprehensive assessment of safety performance and limit further developments of safety methodologies [2]. Due to these limitations, it is needed for researchers to explore other alternatives to crash data, which could be less time consuming and more informative. These alternatives to crashes are referred to as surrogate measures or crash surrogates, which are viewed as proactive measures of safety research.

As early as 1982, Datta et al. [3] suggested that a crash surrogate measure is defined as a quantifiable observation that can be used in place of, or as a supplement to, crash records. Surrogates should have a definite correlation with crashes and thereby to safety-related improvements in roadways. Tarko et al. [4] mentioned that surrogate measures include critical events, such as aggressive lane changing, speeding and red-light turning, acceleration noise, postencroachment time, time-integrated time-to-collision, deceleration-to-safety-time, and even traffic characteristics like volume, speed, and delay. $\mathrm{Wu}$ and Jovanis [5] have critically deliberated on desirable criteria for crash surrogates, stating that a crash surrogate (a) should have a short observation period, (b) should be correlated with clinically meaningful outcomes, i.e., crashes, (c) should be statistically and causally related to crashes, (d) should be affected by a safety treatment similarly to how a safety treatment would affect crashes, and (e) should be "markers" of crashes with a time-scale underpinning, meaning that they should be part of the same sequence of events that produce crashes.

Based on the above definition and criteria, crash surrogates are substitute measures that are likely indicators of crash occurrences, but they occur more frequently than crashes on roadways. Similar to forecasting storms and earthquakes, surrogate measures might be used at a particular location to determine whether an increased 
probability of higher-than-average crash rates is likely. Preventative actions could then be taken when the surrogate measures indicate a high likelihood of future crashes. The main advantage of using surrogates is that they occur more frequently than crashes; therefore, the data on surrogate measures can be collected over a shorter time frame than crashes but with similar statistically significant measures as crash data. In addition, a surrogate measure must have a valid statistical relationship with crashes and be sensitive to traffic safety-related improvements. In practice, data for surrogate measures must be comparatively easier to collect with less manpower, training, and equipment.

Because of the limitations of crash data and the merits of surrogate measures mentioned above, there has been steady progression in the use of surrogate measures in safety analysis [5-10]. Several studies used surrogate measures derived from vehicle trajectories extracted from traffic surveillance videos to assess risk among vehicles [11-13]. Saunier and Sayed [11] extracted vehicle trajectory data from videos recorded at intersections and quantified the probability of collision using traffic conflicts identified by time to collision (TTC). Oh et al. [12] proposed a novel methodology to monitor safety conditions on freeways by detecting hazardous traffic events from videos. Gao and Tian [6] focused on tire skid marks to find the linear correlation between skid marks and crashes collected from selected road segments. St-Aubin et al. [14] proposed a framework for automated vehicle tracking from large-scale traffic video data and showed the potential of using high-resolution vehicle trajectory data for safety analysis using TTC.

Statistically significant positive correlation was found between crash data and conflicts identified by various surrogate measures from various vehicle trajectory data sources in several previous studies [15-18]. Besides, correlating surrogate measures with crash data, many studies have attempted to reveal the relationships between surrogate measures and crash data by developing more advanced statistical modeling approaches. Tarko [19] and Zheng et al. [20] summarized common models of characterizing SSMcrash relationships. Wu and Jovanis [5] developed a conceptual structure.

Using surrogate measures as a means of evaluating safety performance has been sought by many researchers. However, the application of surrogate measures still faces many issues and challenges, for example, the lack of a consistent definition, their validity as an indicator of traffic safety performance, and the reliability of their data. Therefore, this study specifically focuses on documenting the development of surrogates for freeway crashes to provide an effective research method to improve freeway safety.

\section{Methodologies of Studying Surrogate Measures}

The Road Safety Audit program lunched by the FHWA has been implemented in most states. Road Safety Audit is a formal safety performance examination of existing or future roads or intersections by an independent, multidisciplinary team. The task of Road Safety Audit is to identify what elements of the road may present a safety concern to what extent, to which road users, and under what circumstances. The task also includes identifying valid measures to eliminate or mitigate the identified safety problems.

Because a Road Safety Audit does not rely on crash records, the outcome of the Road Safety Audit evaluation is not biased by the crash data. Road Safety Audit also has the ability to observe physical evidence of past crashes, if any, and off-road excursions, such as damages to curbs, roadside barriers, trees, utility poles, delineator posts, and signs; scuff marks on curbs and concrete barriers; tire skid marks, broken auto parts, oil patches on the roads; and vehicle tracks or rutting in the ground adjacent to a roadway. When such evidence concentrates at a particular location, it may be an indication of some safety hazards, and adequate safety mitigation measures could be taken to prevent future crashes. As a result, these types of evidence could have good potential to be used as indicators or surrogates for crashes. Consequently, examination of these factors as potential surrogates will be a primary focus of this study.

The Road Safety Audit program provides new ways of approaching traffic safety issues and identifying promising surrogate measures, which have not received much attention up to now. These potential surrogates included citizen complaints and physical evidence of past crashes and offroad excursions, such as curb damage, tire skid marks, and evidence of broken auto parts.

Tire skid marks were identified as innovative factor in this research. The tire skid marks are usually made by vehicles accelerating/decelerating intensively or changing their motion courses abruptly, so that the vehicle would leave tire marks on the pavement. Because tire skid marks of different characteristics are caused by different situations, different types of skid marks were used to describe different incidents. All skid marks observed were categorized by their shape, intensity, impact, and direction by the authors. Similar work was not found in any previous study. Furthermore, to establish statistical correlation with crash records, the numbers of the skid marks and their locations were two main concerns in the study.

Statistical models are a prevalent tool in studying traffic safety. In this study, the approach was to construct linear regression models between skid marks on the pavement and crash records. If the statistical correlations between them were significant (under a certain confidence level), skid marks were regarded as a crash surrogate.

\section{Correlation Analysis between Skid Marks and Crashes}

The statistical relationship between skid marks and crashes was studied to identify if skid marks could be recognized as a crash surrogate. Two freeway sites were selected for the study.

3.1. Data Collection. Given that there are only two major freeways in the Reno-Sparks area, the freeway sites were selected on both facilities. The study boundaries were 
determined such that each section began and ended at main boundaries of the urbanized area. Thus, the first study section included approximately 10.5 miles of Interstate 80 between Robb Drive (Exit 9) and Vista Boulevard (Exit 21) interchanges. The second section was US Highway 395 (Interstate 580) between Mount Rose Highway/SR 431 (Exit 56) and Panther Valley (Exit 72) interchanges, the distance of approximately 14.8 miles. Both directions of travel on each freeway were evaluated separately, resulting in four freeway sections analyzed in this study.

A map of the study sections is shown in Figure 1.

3.2. Crash Record. To capture the skid mark data, the videos of the pavement surface for each study section were recorded. When filming the videos, every effort was made to maintain a clear viewing angle to simplify the data extraction process. Majority of the videos were recorded early on weekend mornings, in order to encounter fewer vehicles on the roadways, which could block the camera's view of the pavement. Additionally, the research vehicle generally remained as close to the center of the directional roadway as practical. Also, an attempt was made to keep the research vehicle moving at a constant speed generally at or slightly below the posted speed limit (60 mph on freeways).

Once skid mark videos had been obtained and complied, crash records for these areas were requested. So a correlation analysis between the skid marks and crashes could be made. Crash records for the study sections were obtained by courtesy of the NDOT Safety Division.

The crash records for the freeway sections were obtained for the one-year period. Table 1 shows the number of reported crashes by crash type for the freeway study sections. As can be seen in the table, the number of rear-end crashes was more than half of the total crashes occurring in all eight study sections. Because they comprised such a large proportion of the total crashes in each section, rear-end crashes were evaluated separately in addition to the total crash evaluation performed in this study.

The location of reported crashes would become a crucial element in the study. In the provided records, officers responding to crashes typically reported the crash location by its relative distance to a prominent reference point. Thus, it was necessary to ensure that the crash locations were all related to a common referencing system, in order to simplify the analysis. In the case of crashes along freeways, the relative distance and direction to a given point, such as a milepost, cross street, or ramp, were used. This position was then internally modified in NDOT's records to correspond with an actual milepost location referred to as the "Adjusted Mile Marker." Because freeway crash locations were normalized to milepost locations, which are continuous along entire freeway sections, no adjustments were needed by the research team.

3.3. Locating Skid Marks. Once the videotaping was completed, it became apparent that a method was needed to relate the relative location of skid marks found in the videos to the Adjusted Mile Marker or a zero intersection. This is called "study" position. This was necessary for the correlation analysis because the crash records note crash locations relative to its study position. To accomplish this, a relationship between video time, driving speed, and study position was developed for each study section.

Along the freeway sections, the milepost markers were used to determine skid mark locations. The freeways were driven again in order to pinpoint all visible milepost markers erected alongside the highway. After the milepost locations were identified in the field, the video clips were then reviewed in order to determine the video time index where each milepost appeared. Both standard MUTCD mile markers (Figure 2(a)) and NDOT reference panels (found at bridges and other points, Figure 2(b)) were identified. By giving the time index and distance between successive mileposts, original driving speeds on the videos could be estimated. Each freeway section was divided into four or five smaller areas for the purposes of assigning an average travel speed. Based on these calculations, it was possible to assign an approximate milepost location to each skid mark seen in the videos.

In most instances, it was likely that most vehicles leaving a skid mark on the roadway were undergoing a sudden deceleration in a preventative or evasive action to avoid a suddenly stopped car or other obstacles. Thus, it would be reasonable to assume that a collision involving a vehicle that left a skid mark occurred towards the end of the mark. Therefore, when calculating the relative location of skid marks, the downstream end of each mark was used as a reference point for determining the location of a collision.

3.4. Skid Mark Cataloging. Once the logistics of determining skid mark locations was finalized, the videos were extensively reviewed. In reviewing the videos, many areas of the study sections had multiple marks and sometimes overlapping skid marks on the pavement; this was especially apparent along some freeway sections. Also, skid marks usually had distinct characteristics that varied widely. Thus, it was deemed necessary to document and categorize each skid mark individually. The research team identified ten parameters to document based upon the trends and observations made during the video reviews. The two most important parameters were as follows:

(i) Time index: the "time index" parameter is defined as the time position of the video file at which the skid mark occurs. This parameter has two components: the start and the stop time. The starting time begins at the video time stamp in which the skid first appears, and the stop time is the timestamp where the mark disappears from the screen. For the sake of consistency, a uniform method of observing the time index was adopted. The skid mark's relation to the bottom of the video screen was the primary consideration point for recording the video time position. Thus, the start time recorded for each skid mark was the exact second that the leading edge of the of the skid passes out of view on the bottom edge of the screen, and the stop time was the second in which the trailing edge of the mark touched the bottom of the 


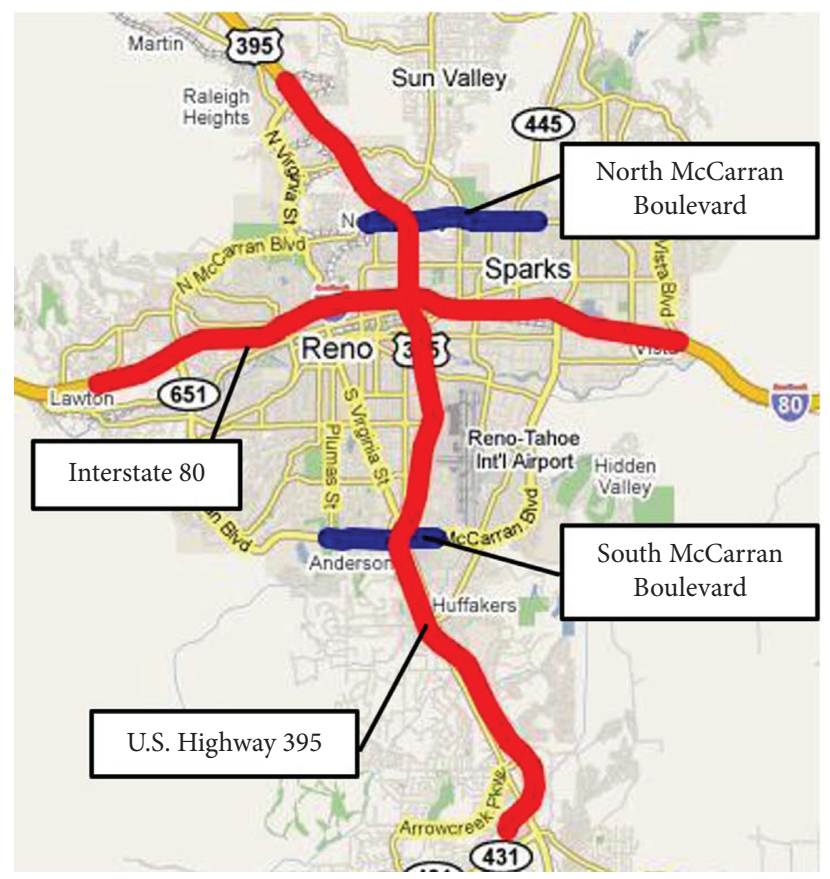

Figure 1: Map of freeway study sections.

TABLE 1: Reported crash types in study sections.

\begin{tabular}{lcccccccc}
\hline \multirow{2}{*}{ Study section } & \multirow{2}{*}{ Direction } & \multicolumn{4}{c}{ Crash type } & \multicolumn{2}{c}{ Total crashes } \\
& & Angle & Noncollision & Rear-end & Sideswipe & Others & Unknown \\
\hline \multirow{2}{*}{ Interstate 80} & EB & 30 & 81 & 134 & 21 & 3 & 6 & 275 \\
& WB & 28 & 56 & 65 & 16 & 2 & 3 & 125 \\
\hline \multirow{2}{*}{ US Highway 395} & NB & 35 & 73 & 283 & 24 & 2 & 8 & 5 \\
& SB & 26 & 77 & 141 & 22 & 2 & 273 \\
\hline
\end{tabular}

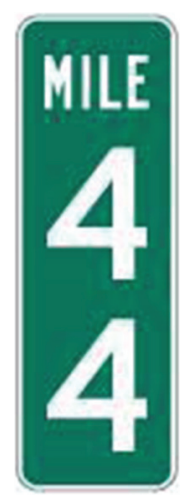

D10-2

(a)

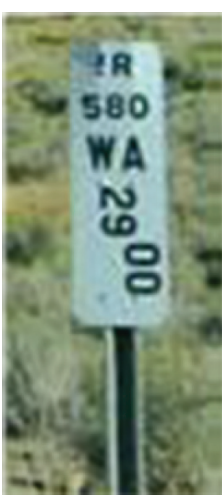

(b)
Figure 2: Milepost panels found along freeway study segments.

video window. In the event that a video skid mark did not touch the bottom of the screen, either the lower side edges of the video were used or the approximate location of the time point (based upon pavement markings or other identifiable features in adjacent lanes) was used to determine the time index. Smaller skid marks that appeared on video for less than one second were recorded with the same start and stop indices.

(ii) Location: the "location" parameter was used to calculate the cumulative distance from the beginning of the study section (on arterials) or the approximate milepost (on freeways), based on the methodology presented in the report. It should again be noted that these calculated locations are estimates only, based on time-space relationships derived from the study videos. Because crashes are more likely to occur at the end of a skid mark, the time index where the trailing end of the skid mark appeared was the point used as the basis for estimating the location of each mark.

Other parameters noted for each skid mark include lane position, whether caused by heavy vehicle, number of wheels on vehicle leaving a mark, direction of the mark, apparent impact to roadside barrier, intensity of the mark, skipping characteristic, and changes in mark width (a more detailed explanation of all the classification parameters can be found in Appendix). The skid marks of different characteristics may serve to predict different types of crashes. For example, 


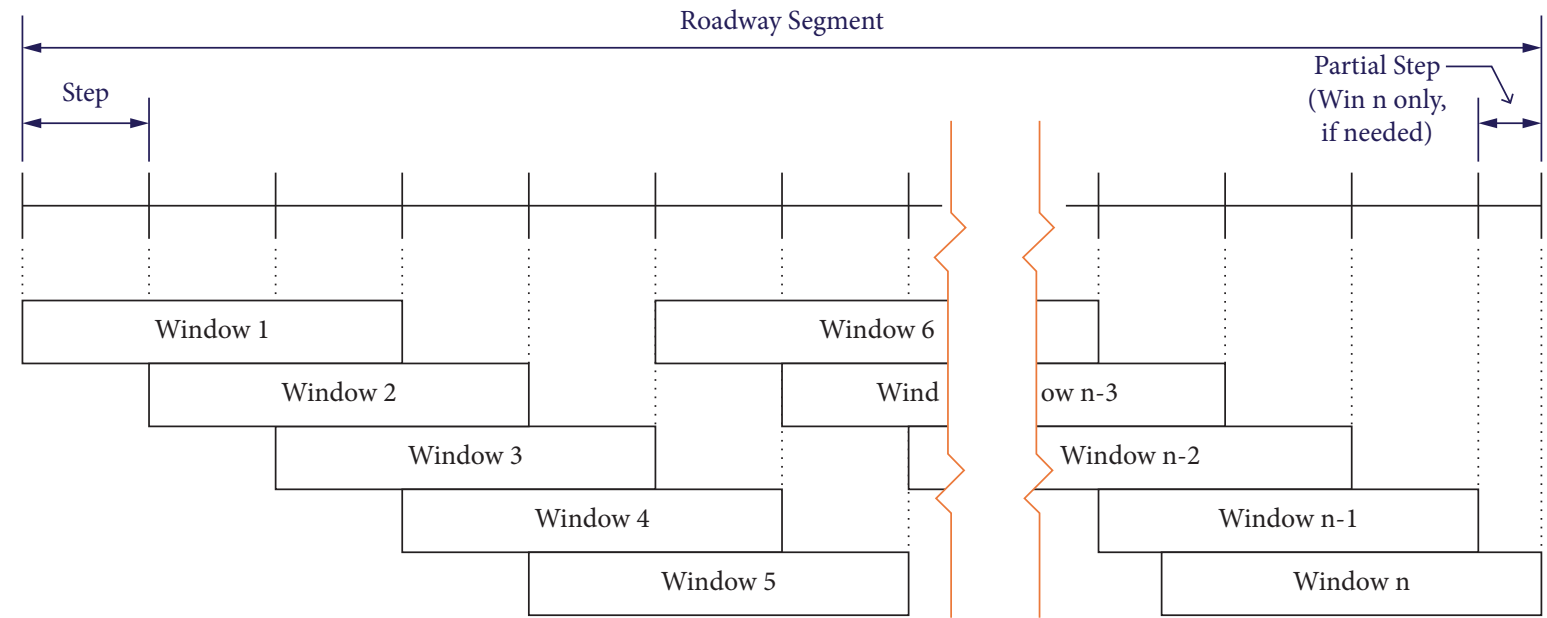

FIGURE 3: Sliding window searching method.

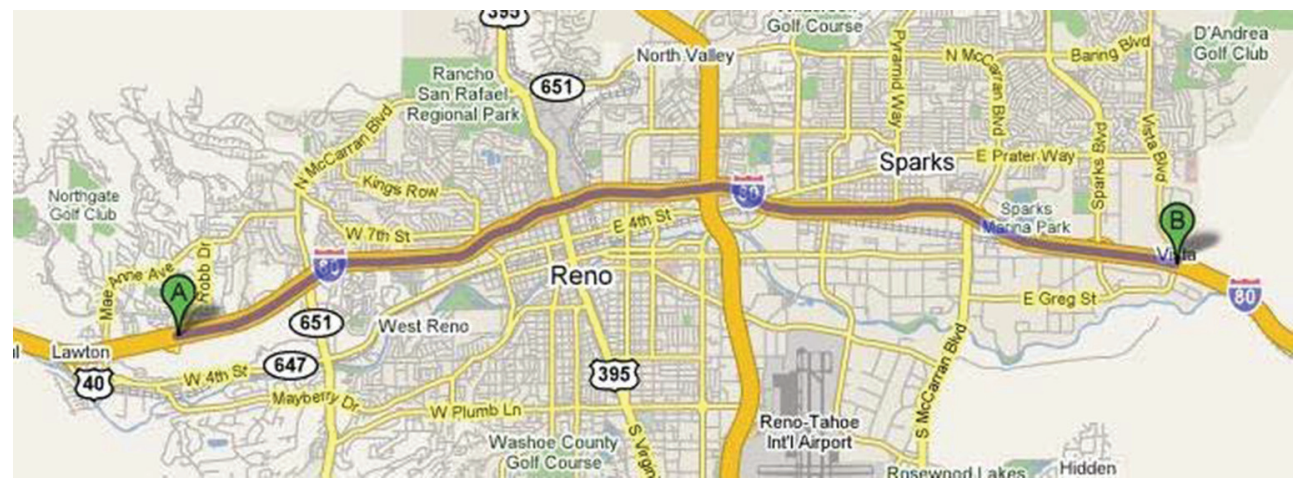

Figure 4: Map of Interstate 80 study sections.

TABle 2: Segment crashes and skid marks on Interstate 80 eastbound.

\begin{tabular}{lcccc}
\hline \multicolumn{2}{c}{ EB segment } & \# of crashes & $\begin{array}{c}\text { \# of rear-end } \\
\text { crashes }\end{array}$ & \# of skid marks \\
$\#$ & Mileposts & & 3 & 7 \\
\hline 1 & $9-10$ & 11 & 3 & 40 \\
2 & $10-11$ & 9 & 2 & 56 \\
3 & $11-12$ & 8 & 4 & 13 \\
4 & $12-13$ & 17 & 36 & 75 \\
5 & $13-14$ & 56 & 66 & 71 \\
6 & $14-15$ & 94 & 11 & 54 \\
7 & $15-16$ & 40 & 9 & 55 \\
8 & $16-17$ & 28 & 6 & 44 \\
9 & $17-18$ & 18 & 7 & 42 \\
10 & $18-19$ & 22 & 3 & 24 \\
11 & $19-20$ & 10 & & \\
\hline
\end{tabular}

skid marks that veered off course might be indicative of sideswipe crashes, or darker skid marks might predict a higher likelihood of rear-end crashes. Ultimately, the analysis undertaken in this research focused on time and location only.

3.5. Data Processing Program and Sliding Window. An interactive program was developed utilizing the Visual Basic macro language within Microsoft Excel. First, the user
TABle 3: Segment crashes and skid marks on Interstate 80 westbound.

\begin{tabular}{lcccc}
\hline \multicolumn{2}{c}{ WB segment } & \# of crashes & $\begin{array}{c}\text { \# of rear-end } \\
\text { crashes }\end{array}$ & \# of skid marks \\
\hline & Mileposts & & 6 & 5 \\
11 & $20-19$ & 9 & 8 & 13 \\
10 & $19-18$ & 17 & 4 & 18 \\
9 & $18-17$ & 12 & 5 & 24 \\
8 & $17-16$ & 17 & 21 & 11 \\
7 & $16-15$ & 44 & 4 & 13 \\
6 & $15-14$ & 31 & 10 & 15 \\
5 & $14-13$ & 21 & 5 & 3 \\
4 & $13-12$ & 16 & 4 & 7 \\
3 & $12-11$ & 15 & 3 & 7 \\
2 & $11-10$ & 7 & 3 & 3 \\
1 & $10-9$ & 6 & & \\
\hline
\end{tabular}

inserted a list of skid mark locations (ordered by cumulative distance or milepost) and the number of skid marks occurring at each location. Next, a corresponding list of crash locations was entered. Then, the user specified starting and ending points, a window, for the analysis. When these variables were entered, the software progressed through each list and calculated the number of skid marks and crashes that were documented within the specified limits of the "sliding window." The window endpoints and the number of skids 


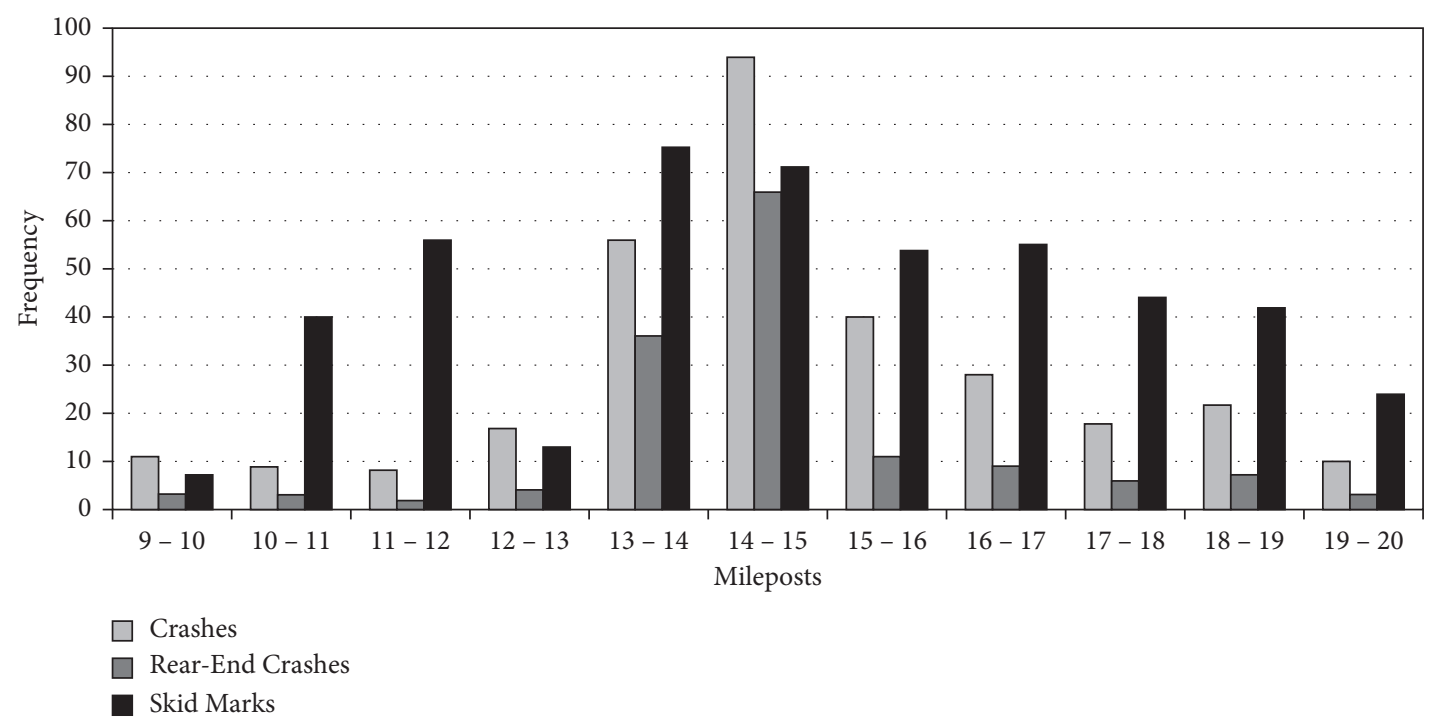

FIgURE 5: Number of crashes and skid marks on Interstate 80 eastbound.

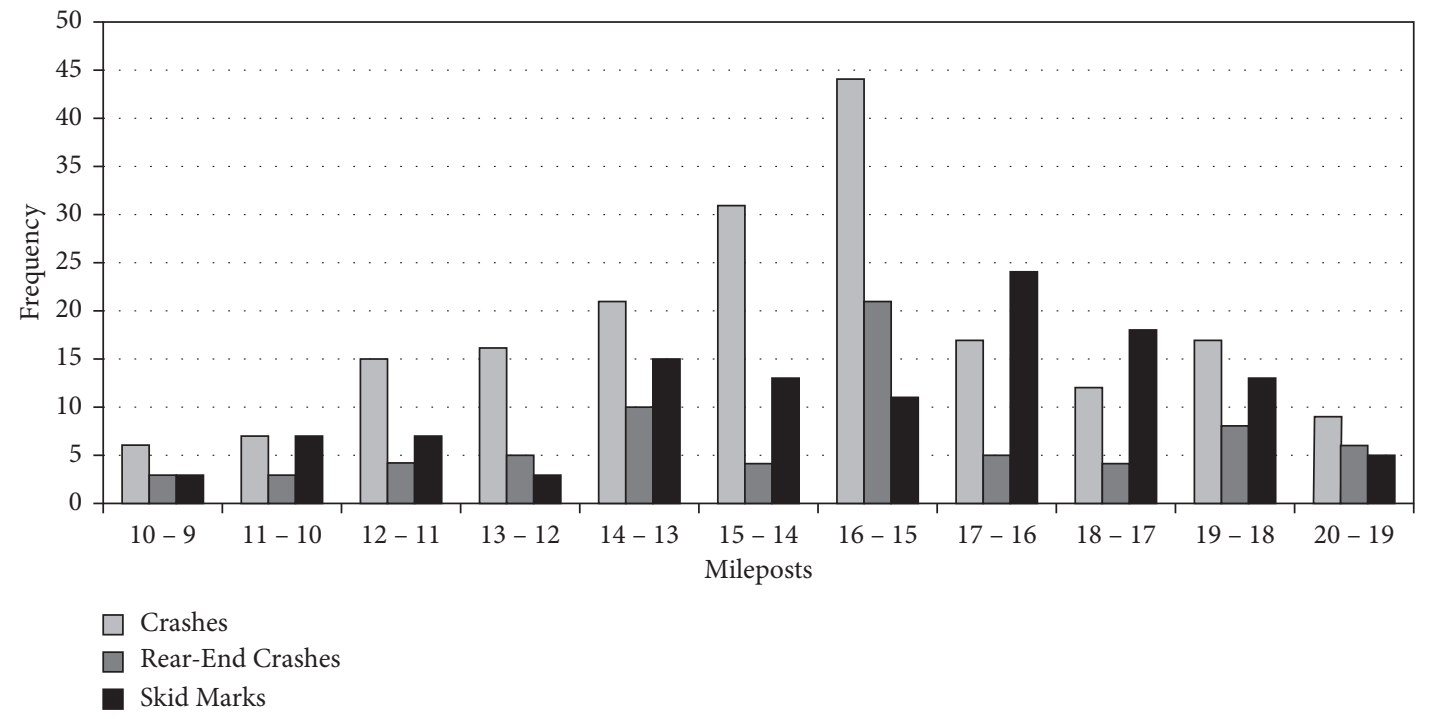

Figure 6: Number of crashes and skid marks on Interstate 80 westbound.

and crashes were outputted into the spreadsheet, which was easily transferred to another document for analysis.

Another function of this program is the capability to utilize the sliding window concept for data analysis as illustrated in Figure 3. For this concept, the window has a user-determined length and slides forward by a small interval specified by the user. The analysis begins with one window at the beginning of the study section. Once the data within the first window are reported, the window "slides" forward by the defined small interval and reports all relevant information in the second window. This process continues until the end of the section is reached. This sliding window method provides for considerable overlap, which is useful in determining where the crashes and skid marks are concentrated. Additionally, the process partitions the study sections into more divisions than intersections or mileposts, and, therefore, it provides a greater number of observations for the regression analyses. This ultimately increases the accuracy of the analysis.

\section{Freeway Analysis}

The study discusses the examination of crash and skid mark correlations along the freeway study sections: Interstate 80 and US Highway 395. The analysis methods of the two freeways are the same, so Interstate 80 is selected as an example for freeway analysis.

Figure 4 shows a map of the study sections along Interstate 80 . The study corridor contains 12 interchanges, with various entrance and exit ramps. The interchanges include the following:

(i) Robb Drive

(ii) McCarran Boulevard West 


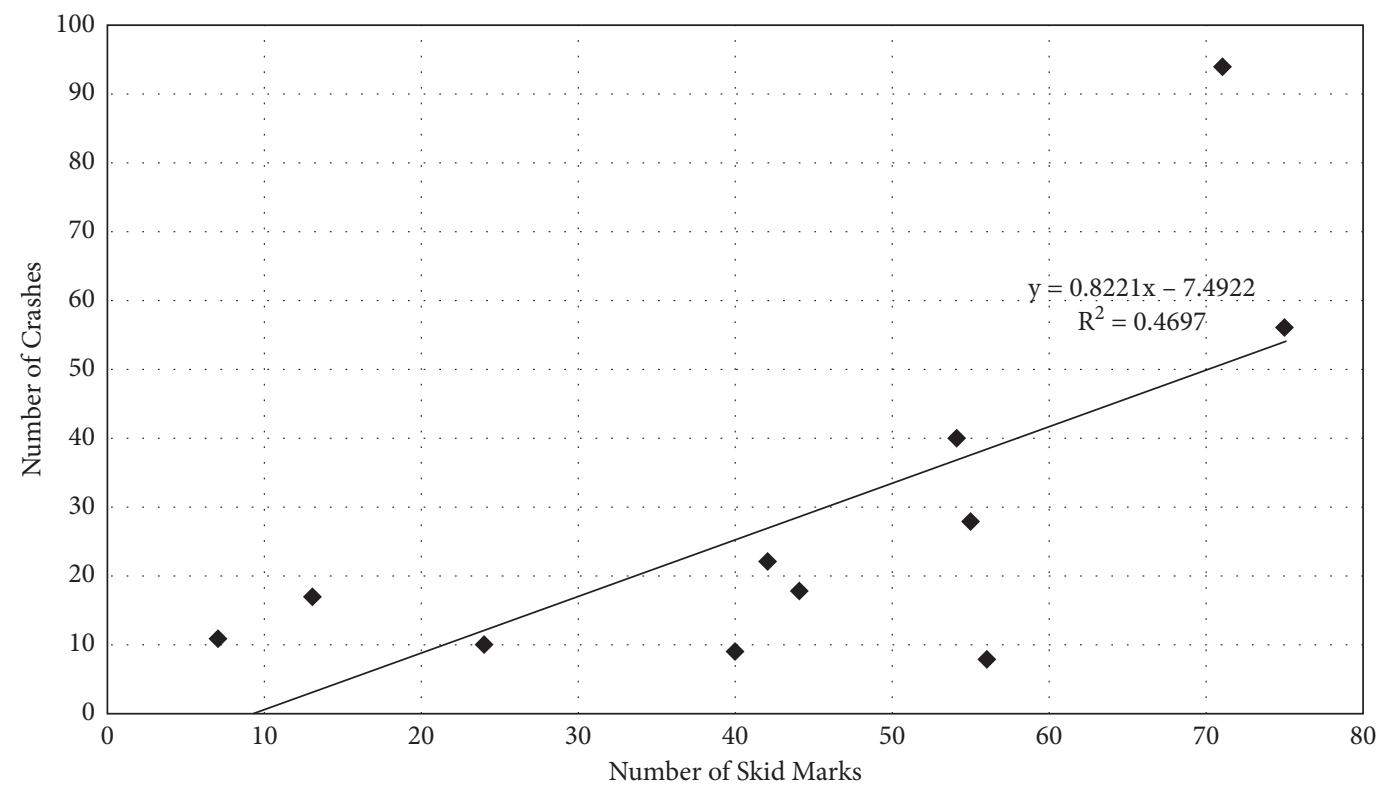

Figure 7: Crash vs. skid correlation by 1-mile segments on Interstate 80 eastbound.

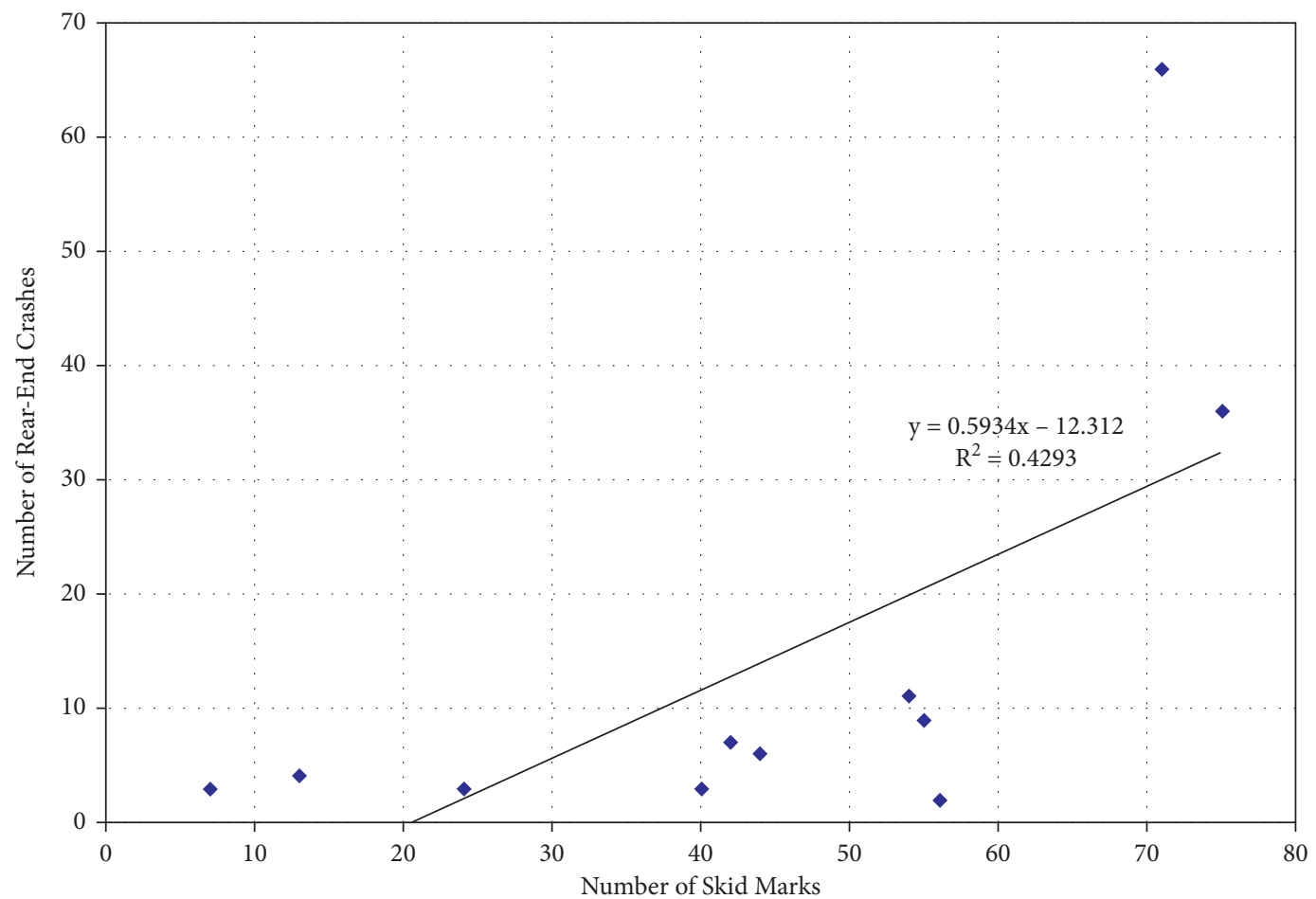

FIGURE 8: Rear-end crash vs. skid correlation by 1-mile segments on Interstate 80 eastbound.

(iii) Keystone Avenue

(iv) Virginia Street

(v) Wells Avenue

(vi) US Highway 395

(vii) Victorian Avenue $/ 4^{\text {th }}$ Street

(viii) Rock Boulevard

(ix) Pyramid Way

(x) McCarran Boulevard East (xi) Sparks Boulevard

(xii) Vista Boulevard/Greg Street

The study position of all crashes and skid marks in these study sections were noted based on the methods discussed previously. Because locations along the freeways were determined based on mileposts, each study section was easily divided into segments based on the mileposts for the analysis. Tables 2 and 3 show information relating to these segments and the number of 


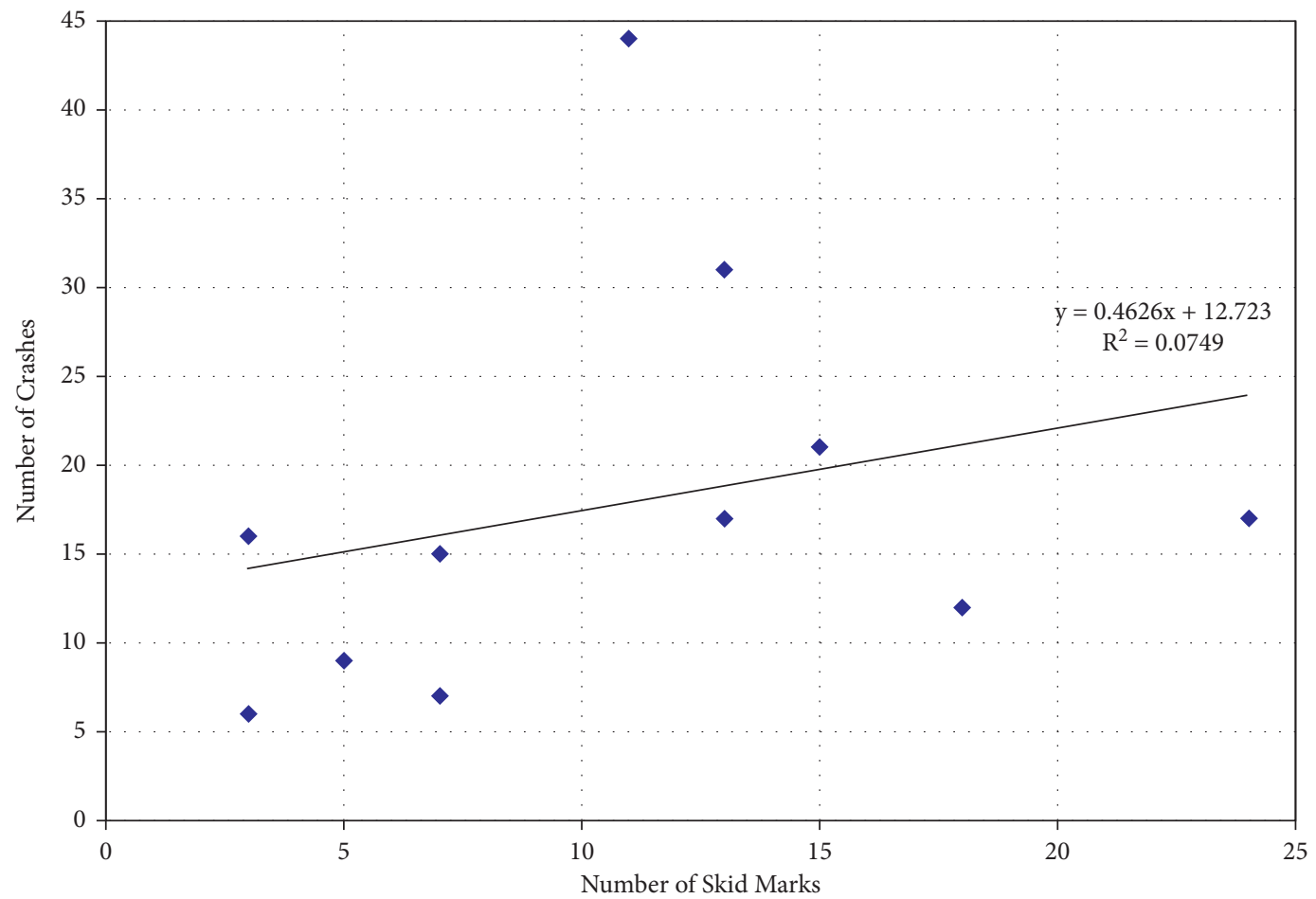

Figure 9: Crash vs. skid correlation by 1-mile segments on Interstate 80 westbound.

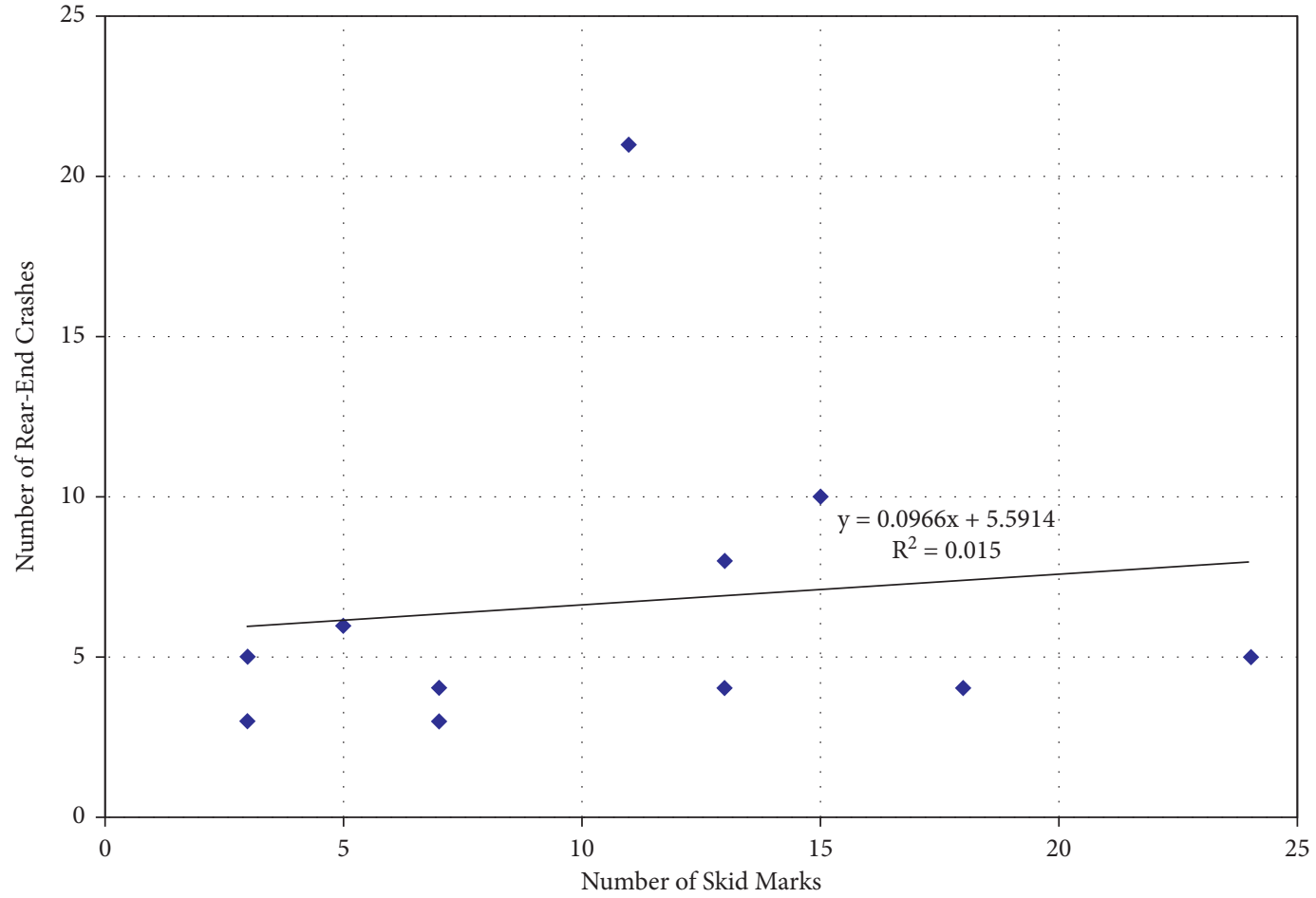

Figure 10: Rear-end crash vs. skid correlation by 1-mile segments on Interstate 80 westbound.

crashes and skid marks in each. The data in these tables are plotted in Figures 5 and 6 . As can be seen in the figures, an increase in the number of skid marks is generally accompanied by an increase in the number of crashes. However, such increases are not always proportional. Additionally, it appears that crashes and skid marks increase towards the center of the study sections. This makes sense intuitively because the center of the study sections is closer to the center of Reno-Sparks and the interchange with US 395 because there are higher 
TABLE 4: $R$-squared values for different regression analyses on Interstate 80 based on various sliding window parameters.

Sliding window parameters

Window length (mi) Step increment (mi) \# of data points
$R$-squared value

Interstate 80 westbound

Interstate 80 eastbound Int
Skids vs. rear-end Skids vs.

Skids vs. crashes $\begin{gathered}\text { Skids vs. rear-end } \\ \text { crashes }\end{gathered} \begin{gathered}\text { Skids vs. } \\ \text { crashes }\end{gathered}$ Skids vs. rear-end crashes

\begin{tabular}{ccccccr}
\hline & 0.2 & 51 & 0.51 & 0.53 & 0.17 & 0.22 \\
1 & 0.1 & 101 & 0.51 & 0.53 & 0.15 & 0.21 \\
& 0.05 & 201 & 0.51 & 0.53 & 0.15 & 0.21
\end{tabular}

$\begin{array}{lll}0.53 & 0.15 & 0.21\end{array}$

\begin{tabular}{ccccccc}
\hline & 0.2 & 54 & 0.42 & 0.46 & 0.11 & 0.12 \\
0.12 & 0.47 & 0.09 & 0.11 & 0.12 \\
\hline \multirow{2}{*}{0.25} & 0.1 & 106 & 0.41 & 0.47 & 0.08 & 0.03 \\
& 0.05 & 211 & 0.41 & 0.38 & 0.02 & 0.04 \\
\hline
\end{tabular}

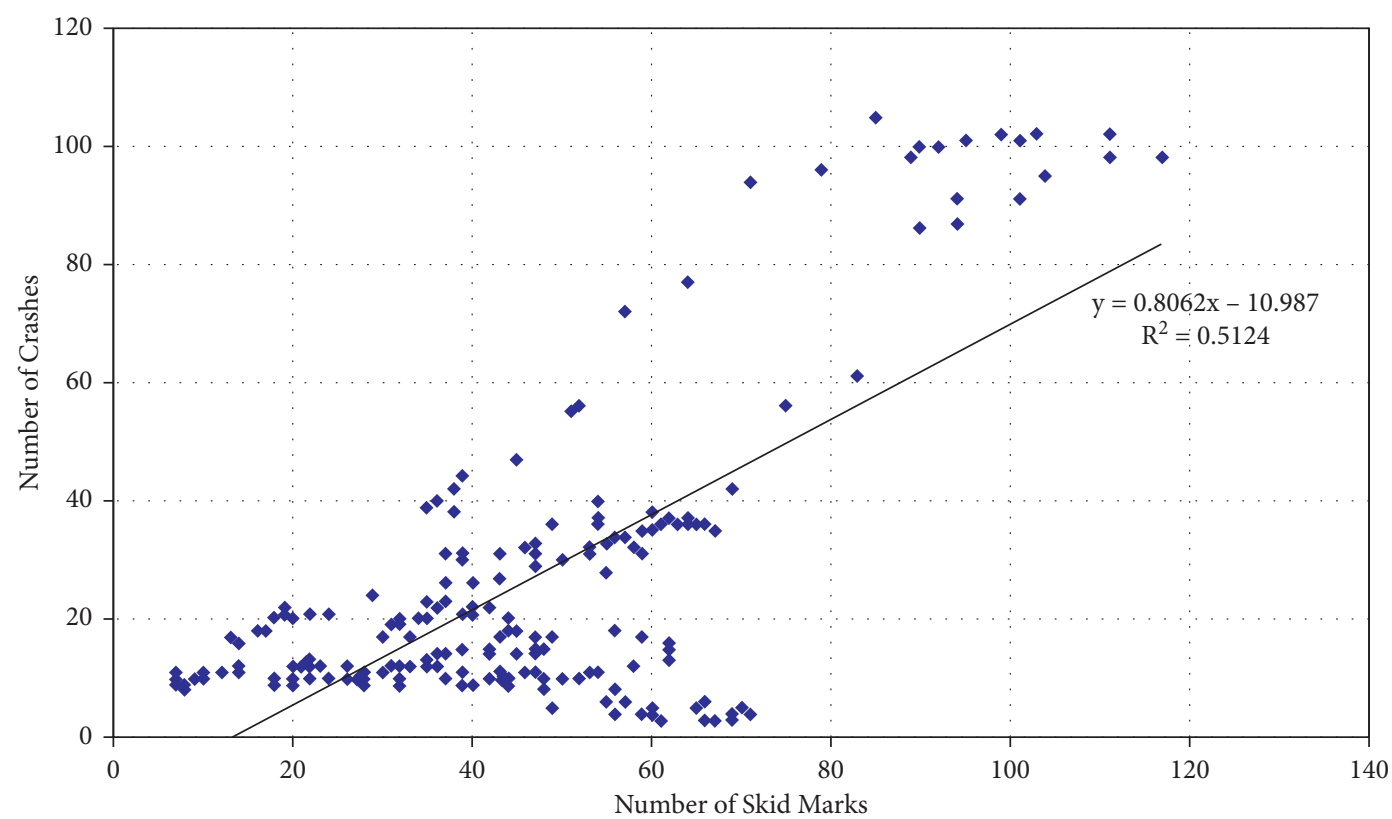

FIGURE 11: Sliding windows crash vs. skid correlation on Interstate 80 eastbound (1.0-mile windows, 0.05 -mile step).

traffic volumes. One interesting note is that there are considerably more crashes and skid marks observed along the eastbound section than the westbound section as described next.

Utilizing the data in Tables 2 and 3, linear regression modeling was used to analyze the relationship between the frequency of skid marks and the frequency of crashes and also between skid mark frequency and rear-end crash frequency in each segment. Graphs depicting the results are given in Figures 7 through 10 .

For the eastbound direction, it can be seen in Figures 7 and 8 that both the skid vs. crash and skid vs. rear-end crash regressions produced good trend lines. The $R$-squared value of both correlations was above 0.4 , which suggested average correlation between the skid marks and crashes. In Figures 9 and 10, the trend lines were positive for both the crash and rearend crash scenarios, but the $R$-squared values for both analyses were lower than 0.1 , indicating poor linear correlation.
Analyzing data based on 1-mile consecutive segments alone did not provide a comprehensive analysis. As an example, such examinations will not show a potential small segment with the highest frequencies of skid marks or crashes if it were to spread across any milepost. For this reason, the sliding window concept was also applied to the freeway sections. By shifting the analysis window gradually along the freeway, specific ranges of locations can be studied, thus providing additional data and insight into the analysis.

Multiple scenarios of window length and forward step increments were initially studied: 1 -mile windows with $0.2-$, 0.1 -, and 0.05-mile steps; 0.5-mile windows with $0.2-, 0.1-$, and 0.05 -mile steps; and 0.25-mile windows with 0.1 - and 0.05-mile step. Using the outputs of these scenarios, linear regression analysis was performed to again test the relationship between crashes and skid marks for each sliding window. Table 4 lists the $R$-squared value for each of these regressions. 


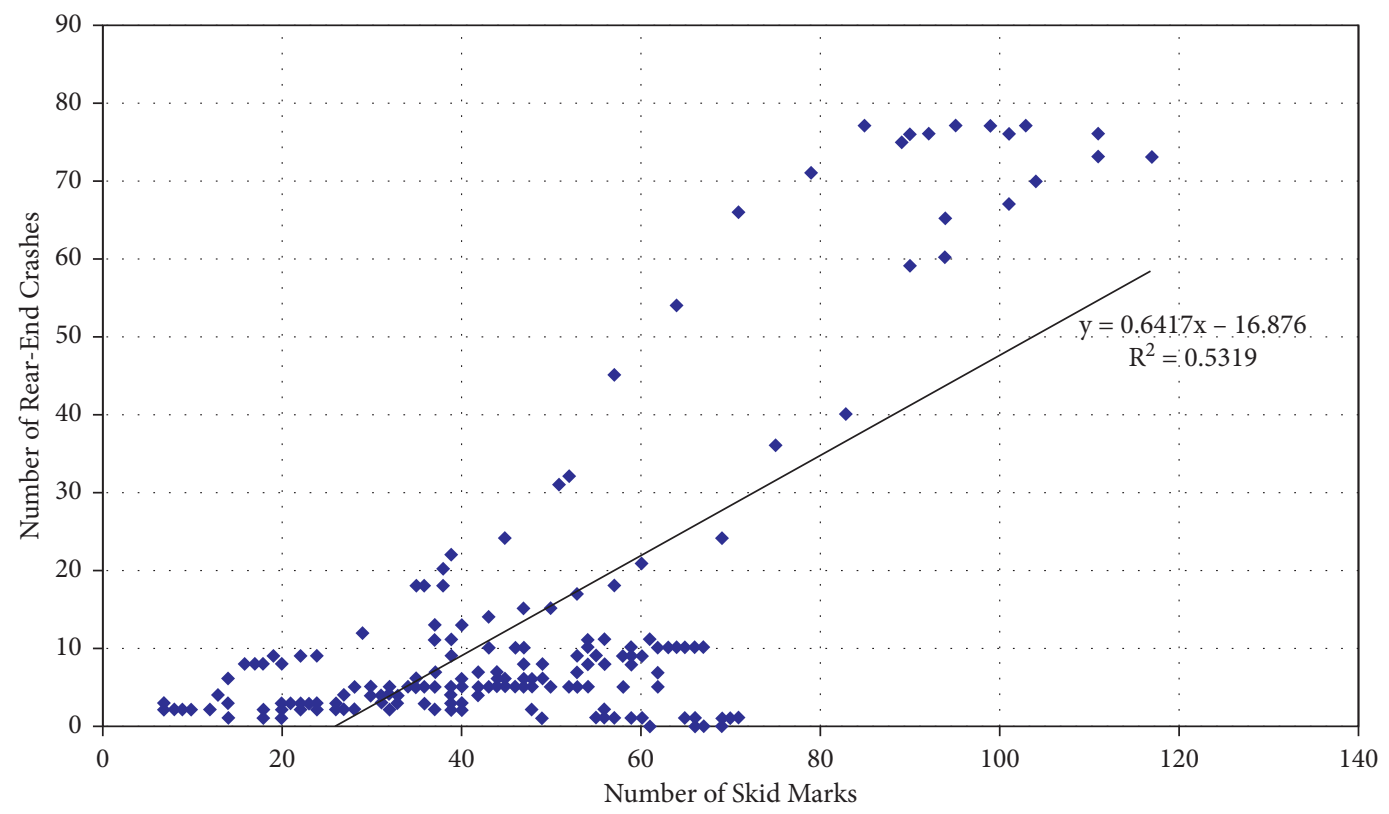

Figure 12: Sliding windows rear-end crash vs. skid correlation on Interstate 80 eastbound (1.0-mile windows, 0.05 -mile step).

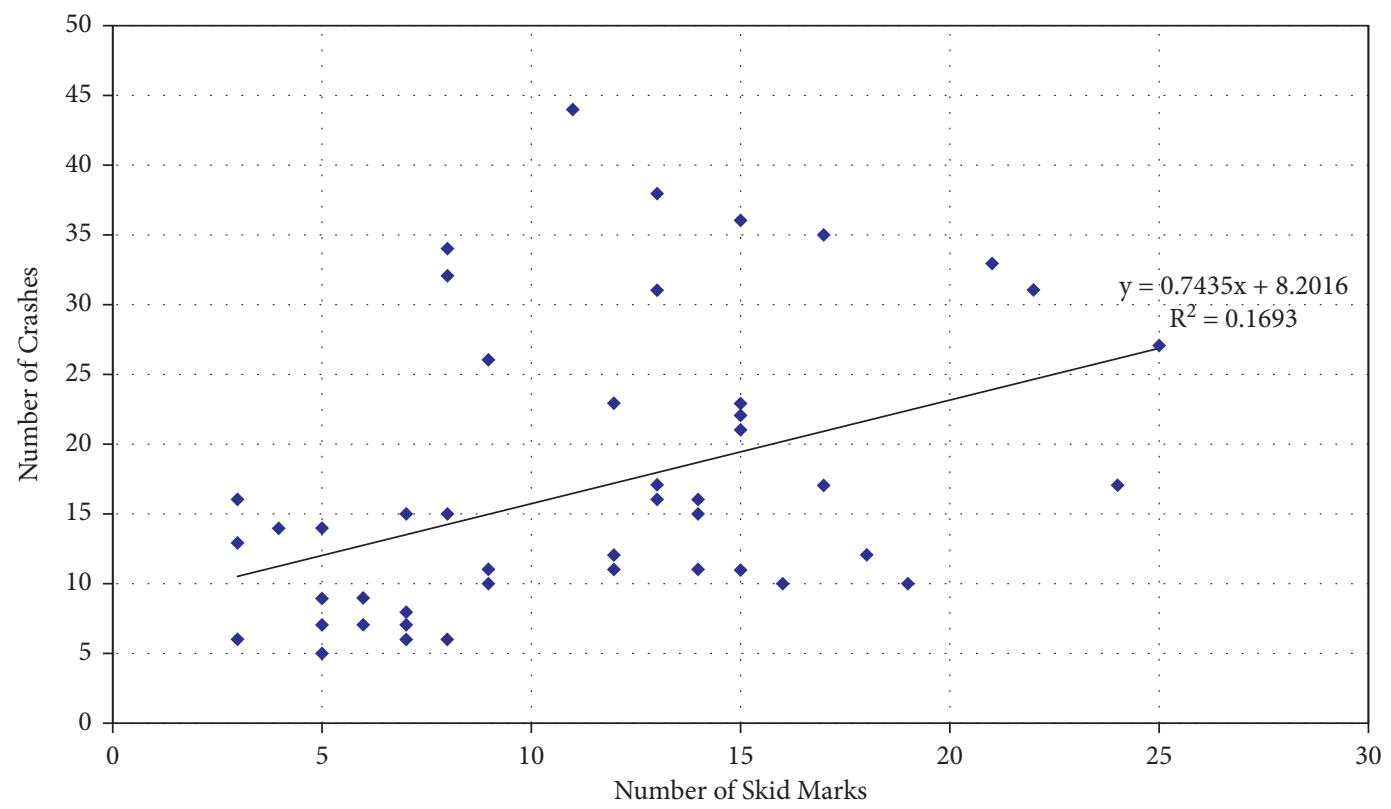

FIGURE 13: Sliding windows crash vs. skid correlation on Interstate 80 westbound (1.0-mile windows, 0.20 -mile step).

As can be seen in Table 4, regressions using a 1-mile window produced the best correlations between skid marks and crashes, although the step increments varied between the best regressions. Additionally, regressions using rear-end crashes only achieved slightly better $R$ squared values along Interstate 80 eastbound and much higher values than the counterparts in the westbound direction.

The regressions from Table 4 obtaining the highest $R$ squared values were selected for further analysis. For Interstate 80 eastbound, however, the best regression on the skids versus crashes had a different sliding window step increment than the skids versus rear-end crashes regression; both regressions using a 0.05-mile step increment were used in order to make similar comparisons. Figures 11 through 14 show the results of the regression using sliding windows. As can be seen, both directions of Interstate 80 have positive trends using the sliding window method. Eastbound sections have the better correlation, with the rear-end crash correlation being slightly superior.

Based on the sliding window outputs, frequencies of crashes and skid marks are plotted in Figures 15 and 16 . In these graphs, the $x$-axis represents the milepost location of the starting point of each mile-long sliding widow. The frequency of crashes and skid marks of any 1-mile segment can be determined by 


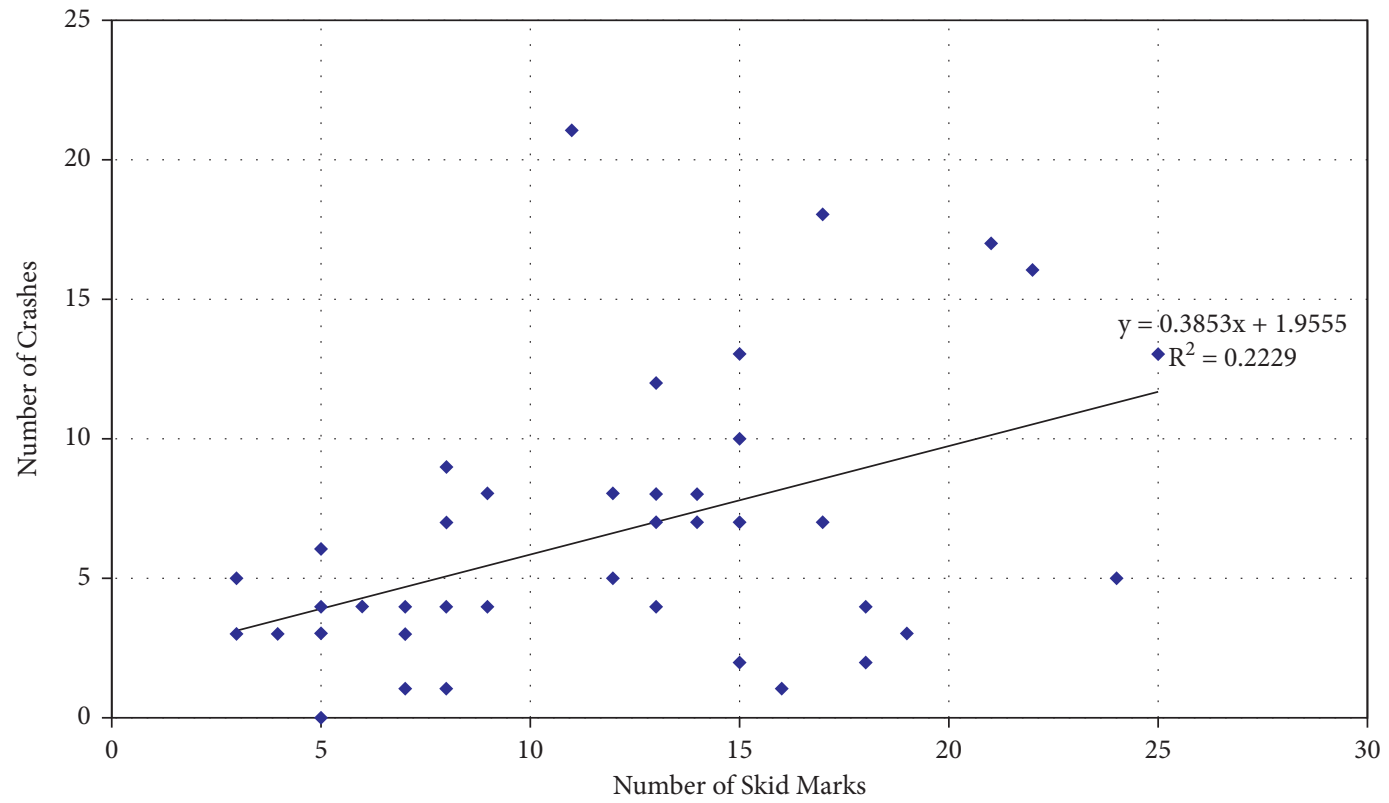

FIgURE 14: Sliding windows rear-end crash vs. skid correlation on Interstate 80 westbound (1.0-mile windows, 0.20 -mile step).

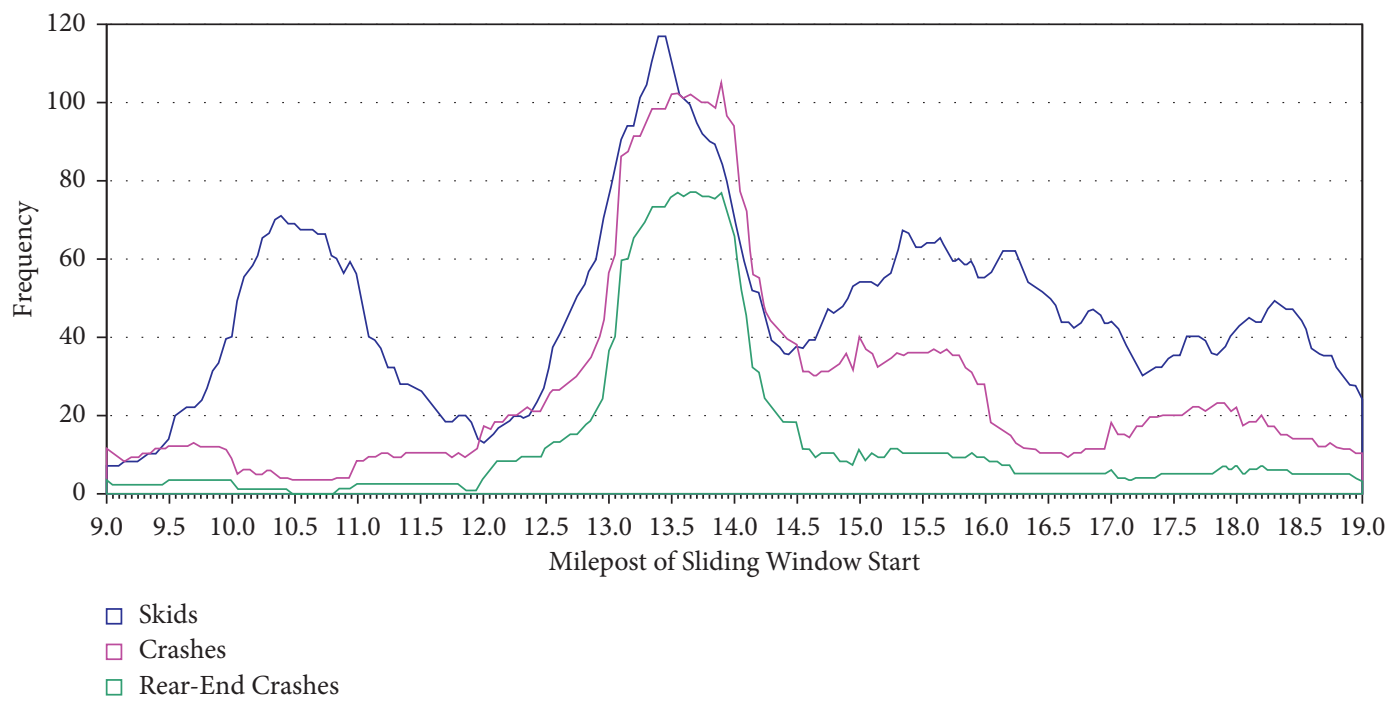

FIGURE 15: Sliding windows crash/skid frequency on Interstate 80 eastbound (1.0-mile windows, 0.05-mile step).

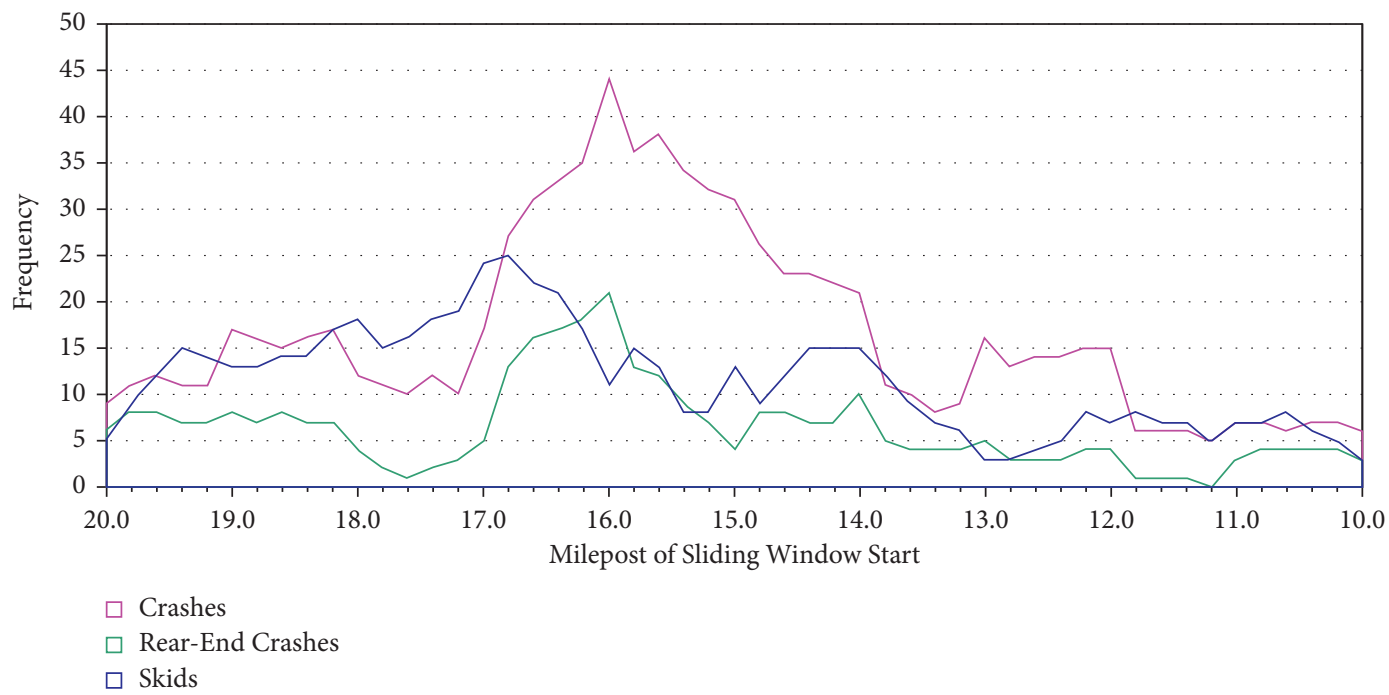

FIGURE 16: Sliding windows crash/skid frequency on interstate 80 westbound (1.0-mile windows, 0.20 -mile step). 


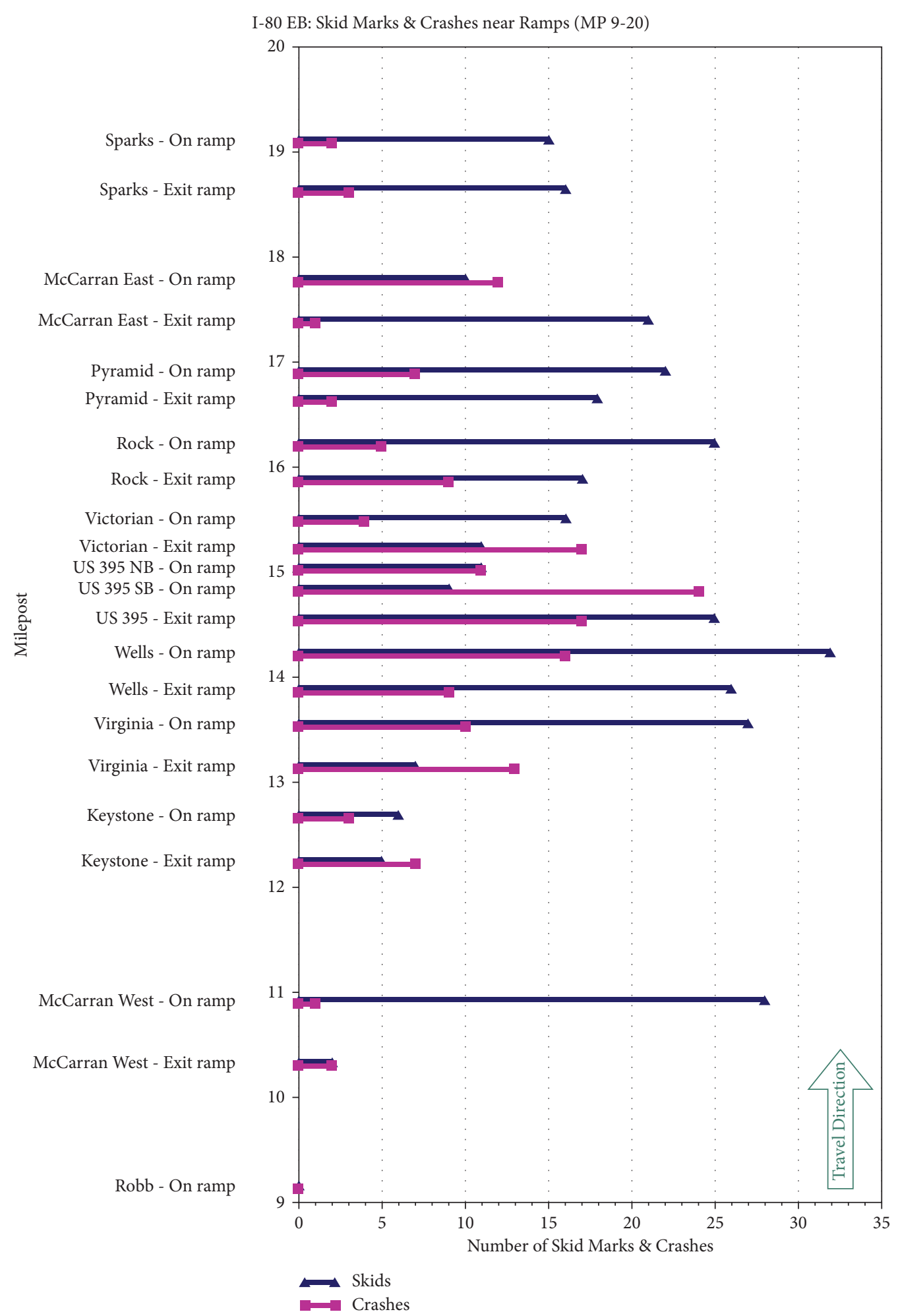

FIgURE 17: Crashes and skid marks at Interstate 80 eastbound ramps.

looking at the area under the graph for the beginning of the selected area.

Following the eastbound section of Interstate 80, one can notice several locations where the skid marks spike, namely, beginning near milepost 10 , mileposts $13-14$, and near mileposts $15.50-16.50$. However, crashes and rear-end crashes only seem to have similar spikes around milepost 13-14 and to a lesser extent near milepost 15.50. These might be plausible to consider as locations needing attention. In the westbound section, the only major spike seems to be the area beginning roughly near mileposts $16.6-15.6$. For this case, the number of crashes outnumbers skid marks. It was 


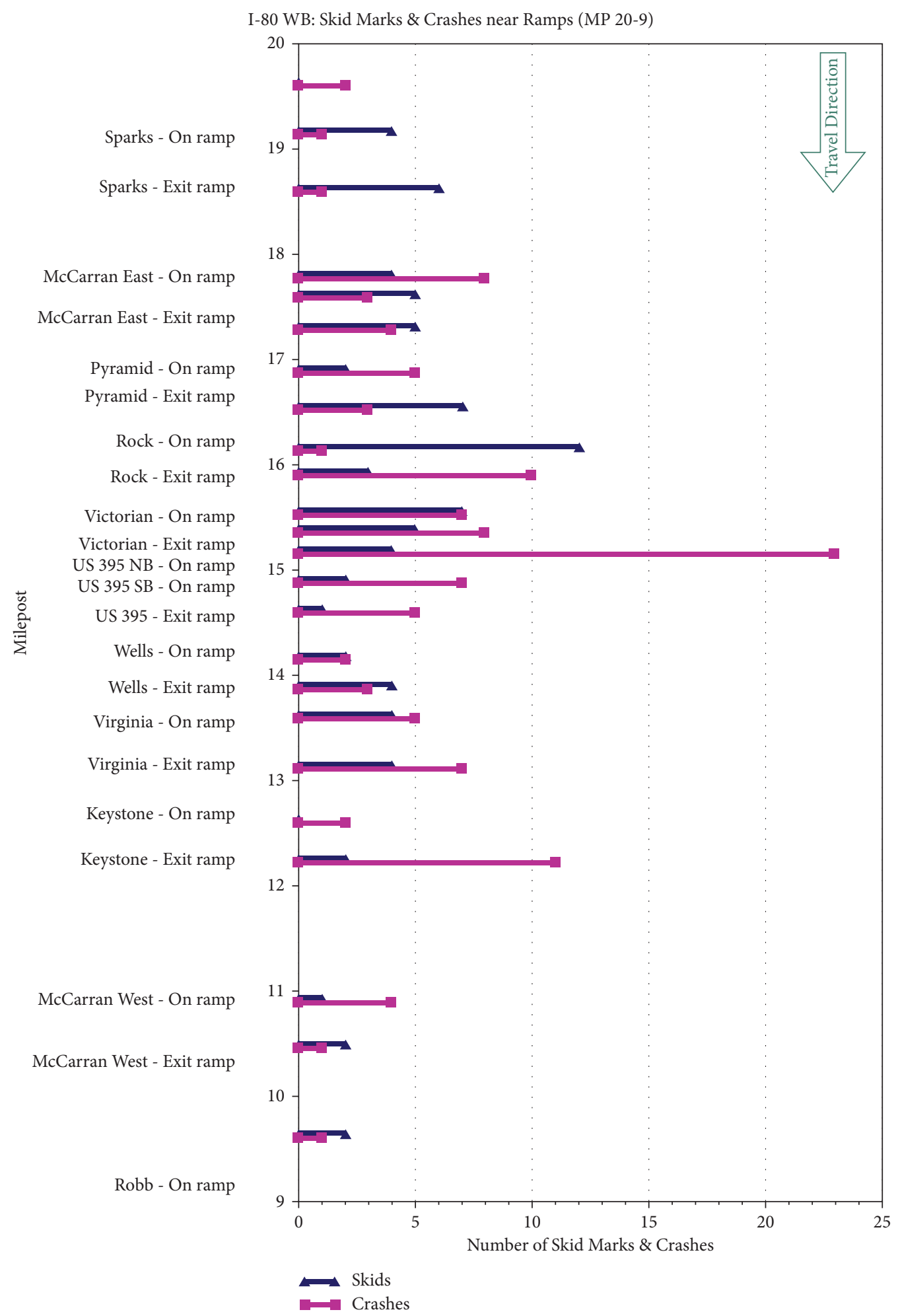

Figure 18: Crashes and skid marks at Interstate 80 westbound ramps.

noticed that all the locations mentioned above usually have high volumes coming from the freeway interchange at busy surface roadways, for example, North Virginia Street, North McCarran Boulevard, Rock Boulevard, and Pyramid Way.
In all the above analyses, it was recognized that examining these freeway sections with a given distance does not consider possible effects due to vehicles weaving near interchanges. Thus, additional analyses were performed pertaining solely to freeway entrance and exit ramps. For this examination, the exit ramp 


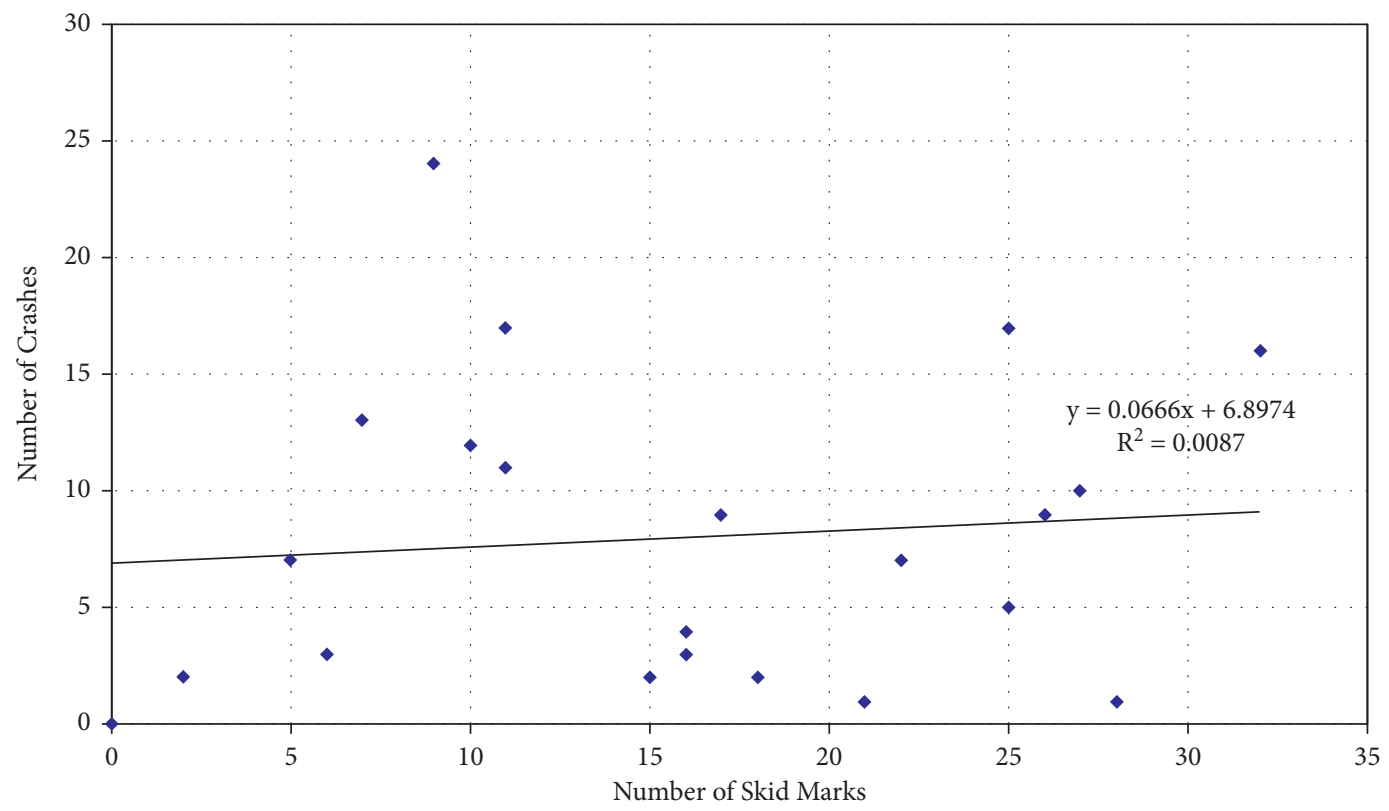

FIGURE 19: Crash vs. skid correlation at Interstate 80 eastbound ramps.

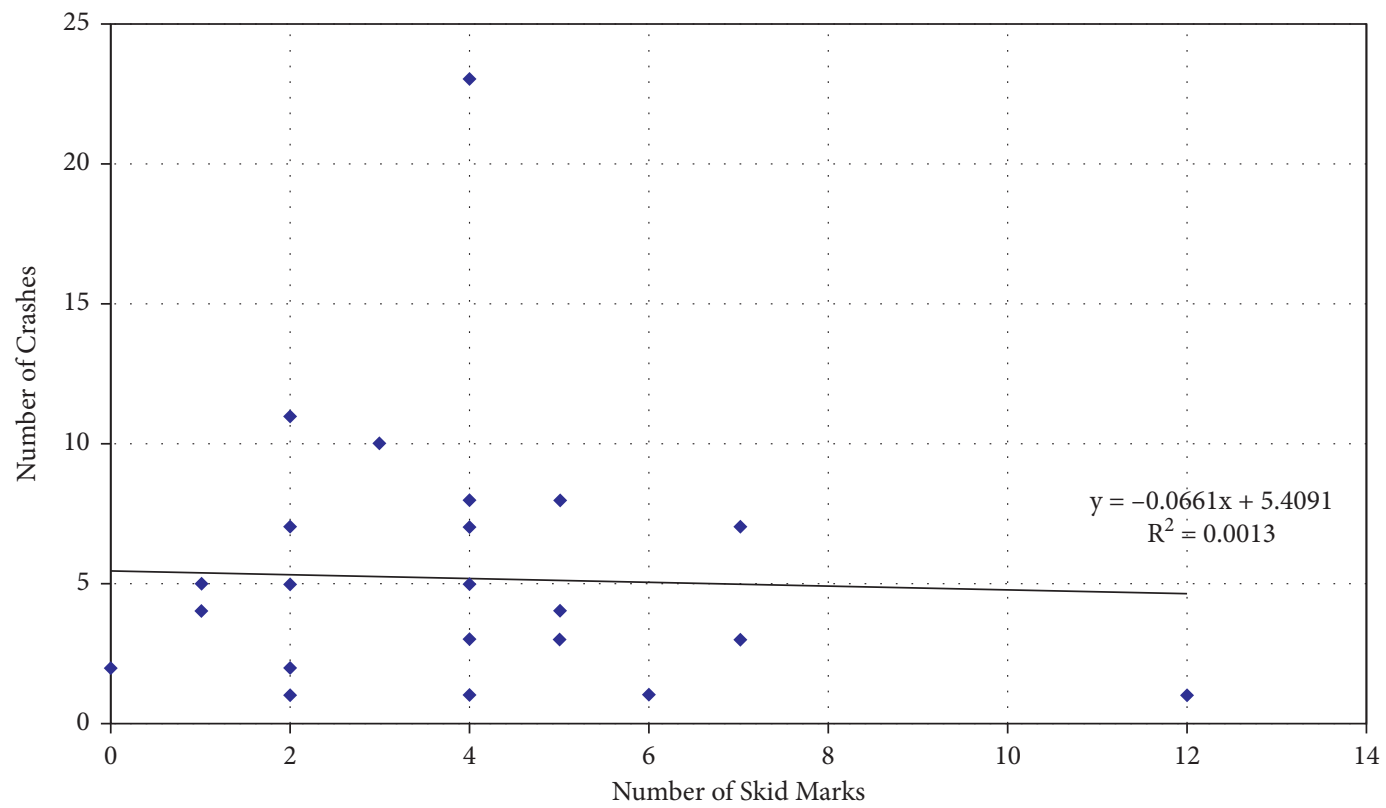

FIGURE 20: Crash vs. skid correlation at Interstate 80 westbound ramps.

areas studied consisted of the distance between the physical gore of the off ramp and 0.30-miles upstream, whereas the entrance ramps used the distance from physical gore to 0.30 miles downstream. The 0.30 -mile distance was selected based on a definition used by Safety Analyst documentation as the boundary of the "interchange influence area" [21].

Figures 17 and 18 give a graphical representation of the number of skid marks and crashes for each freeway ramp within the eastbound and westbound study sections, respectively. As can be seen, the number of skids and crashes did not necessarily correspond because the highest skid mark location is not the same as the highest crash location.

Figures 19 and 20 present the results of a regression given all the ramp data for a direction of freeway. As evidenced by the figures, it is unlikely that any correlation exists. Each section obtains from the regression an $R$-squared value below 0.01 , and the westbound regression produces a negative trend. These facts indicate that a very poor correlation exists between crashes and skid marks when only ramps were considered. 
TABLE 5: Regression outputs for freeways.

\begin{tabular}{|c|c|c|c|c|c|c|c|}
\hline & \multirow[t]{2}{*}{ Freeway stretch } & \multirow[t]{2}{*}{ Segmentation scale } & \multirow[t]{2}{*}{ Direction } & \multicolumn{2}{|c|}{$\begin{array}{c}\text { Regression } \\
\text { equation }\end{array}$} & \multirow[t]{2}{*}{$P$ value of slope } & \multirow[t]{2}{*}{$R$-square } \\
\hline & & & & Slope & Intercept & & \\
\hline \multirow{8}{*}{ Crashes vs. skid marks } & \multirow{4}{*}{ Interstate 80} & \multirow{2}{*}{ Milepost } & $\mathrm{EB}$ & 0.82 & -7.49 & 0.02 & 0.47 \\
\hline & & & WB & 0.46 & 12.72 & 0.42 & 0.07 \\
\hline & & \multirow{2}{*}{ Sliding window } & $\mathrm{EB}$ & 0.81 & -10.99 & $\leq 0.001$ & 0.51 \\
\hline & & & WB & 0.74 & 8.20 & $\leq 0.001$ & 0.17 \\
\hline & \multirow{4}{*}{ US Highway 395} & \multirow{2}{*}{ Milepost } & NB & 1.48 & 0.81 & $\leq 0.001$ & 0.85 \\
\hline & & & SB & 1.66 & 10.50 & $\leq 0.001$ & 0.52 \\
\hline & & \multirow{2}{*}{ Sliding window } & NB & 1.30 & 0.00 & $\leq 0.001$ & 0.88 \\
\hline & & & SB & 1.69 & 9.01 & $\leq 0.001$ & 0.55 \\
\hline \multirow{4}{*}{ Rear-end crashes vs. skid marks } & \multirow{2}{*}{ Interstate 80} & \multirow{2}{*}{ Milepost } & $\mathrm{EB}$ & 0.59 & -12.31 & 0.03 & 0.43 \\
\hline & & & WB & 0.10 & 5.59 & 0.72 & 0.01 \\
\hline & \multirow{2}{*}{ US Highway 395} & \multirow{2}{*}{ Milepost } & $\mathrm{NB}$ & 1.24 & -4.91 & $\leq 0.001$ & 0.84 \\
\hline & & & SB & 1.01 & 4.24 & $\leq 0.001$ & 0.50 \\
\hline
\end{tabular}

\section{Concluding Remarks}

This study discussed a detailed analysis performed to ascertain whether tire skid marks on a pavement surface can be used to predict crashes or determine locations with possible safety concerns. Study sections on freeways in the RenoSparks urbanized area were identified to analyze and in order to make this determination. Video recordings documented positions of the skid marks along the roadways in the study. NDOT crash records provided locations where reported crashes had occurred. Based on these data, linear regression techniques were utilized to discover whether skid marks and crash data were indeed correlated. Considering rear-end crashes comprise a large proportion of all types of crashes (referred as crashes in this study), linear relationship between rear-end crashes and skid marks were also examined.

Table 5 presents the results from the linear regression analyses for the study freeway segments. Given that all slopes are consistently positive, it is reasonable to conclude that crashes/rear-end crashes generally increase as the skid marks increase in our cases. Additionally, except for the westbound direction of Interstate 80 under milepost scale, the $P$ values for regression slopes are small (values italicized in Table 5), which provides strong evidence that skid mark frequency contains useful information in explaining and predicting crashes/rear-end crashes, given a confidence level of $95 \%$. Also, the $R$ squared values of all scenarios were examined to evaluate the correlation between frequencies of skid marks and crashes/rear-end crashes, and the closer the value is to 1 , the greater the degree of linear association between them. Thus, based on the regression results of crashes vs. skid marks, by comparing the outputs of the same freeway stretch of any direction under two division scales, it is found that regressions supported by sliding windows yield higher $R$-squared values than those supported by mileposts. This suggests that the linear association between skid marks and crashes is relatively stronger using sliding windows. In addition, given the fairly high $R$ - squared values on most of the stretches (except for Interstate 80 westbound for crashes vs. skid marks and Interstate 80 westbound for rear-end crashes vs. skid marks), linear correlation between skid marks and crashes might exist in these cases (values underlined in Table 5).

For the freeway sites, finding pertaining tire skid marks are summarized as follows:

(a) Crashes/rear-end crashes generally increased with increasing skid marks

(b) Skid-mark frequency is a suitable predictor of crash/ rear-end crash frequency in most of the scenarios (87.5\% for crash scenarios and $75 \%$ for rear-end crash scenarios) with a confidence level at $95 \%$

(c) In most scenarios, skid marks and crashes showed good linear correlation as indicated by relatively high $R$-squared values

Due to strong correlation between tire skid marks and crashes on the selected freeway segments, more case studies need to be initiated on freeways in other urban areas. Also, additional work should be conducted to study how the tire skid marks could be used to help determine crash mitigation measures.

\section{Appendix}

\section{Skid Mark Catalog Parameter Definitions}

Lane: the "lane" parameter is defined as the lane of the roadway in which the skid mark occurs. In the event, a single skid mark follows a path through more than one lane, the lane in which the skid first appears was identified for the purposes of this parameter (with appropriate notation given in the notes column). The numbering of travel lanes and turn lanes followed the conventional road lane numbering schemes. The leftmost lane (i.e., the lane closest to the median/center 
line) was designated lane 1 , with lane numbers increasing with each consecutive travel/turn lane to the right of the center line.

Heavy vehicle: the " $\mathrm{HV}$ " parameter indicates whether or not a skid mark appears to have been caused by the actions of a heavy vehicle. For the purposes of classifying this parameter, a heavy vehicle was defined as a truck, bus, trailer, or other commercial vehicle, which typically features four or more wheels on its rear axle. If two skid marks were closely spaced on one side of a lane, began and ended at approximately the same point, and follow one distinct path, then the marks were indicated to have been caused by a heavy vehicle.

Wheels: the "wheels" parameter indicates whether the actions of a single vehicle left behind skid marks on one or both sides of the vehicle. If a set of skid marks were on opposite sides of a lane, began and ended at approximately the same point, and followed a similar trajectory, then the marks were assumed to have been formed by both the left and right side tires of a single vehicle. Otherwise, if a skid mark appeared singularly and was aligned closer to the left or right side of the lane, then the mark was assumed to have been formed by either the left or right side tires of a single vehicle, respectively. For other singular skid marks aligned near the center of a lane, it was difficult to ascertain which side of the vehicle formed the mark (or whether the mark was made by a motorcycle) without additional information.

Direction: the "direction" parameter indicates the approximate direction the vehicle was heading when it formed the skid mark. This parameter was given three basic severity levels of straight, veered, or swerved, based on the apparent trajectory suggested by the skid mark. A skid mark in which the mark mostly paralleled the lane line markings was considered to be a straight mark. Any skid mark that shifted slightly to one side (but still remained mostly parallel to the lane line) and did not cross a lane line was also considered to be a straight mark. A skid mark was considered to veer when the mark gradually encroached upon an adjacent lane or lane line. Skid marks that followed a direct path into the adjacent lane and those that encroached upon the adjacent lane at the end of a predominantly straight path were also considered to be veering marks. Generally, a skid mark considered to veer had a long length and trajectory oriented primarily in the direction of travel. As a rule of thumb, skid marks deviating less than approximately $30^{\circ}$ from the center line of the original lane were considered to veer. A skid mark was considered to swerve when the mark suddenly or drastically crossed into one or more adjacent lanes. Generally, a swerve was a skid mark that curved sharply away from the originating lane and took a trajectory oriented more perpendicular to the direction of travel. As a rule of thumb, skid marks appearing to deviate more than $30^{\circ}$ from the center line of the original lane were considered to swerve. Some swerve marks first swerved one direction and then in another. In such instances, the initial swerve direction was indicated under this parameter, with additional swerves mentioned in the Notes section.

Impact: the "impact" parameter indicates whether the vehicle that caused the skid mark appears likely to have impacted the roadside barrier (dividing wall, guardrail, median, etc.). Determination of this parameter is based on the location and trajectory of the skid mark in relation to the barrier, as well as the appearance of deformations or repairs on the barrier. Generally, a skid mark that indicates a barrier impact has also veered or swerved from its original trajectory.

Intensity: the "intensity" parameter is a relative measure of the darkness of the skid mark. This parameter was given three basic severity levels, based upon the contrast of the color of the skid mark versus the color of the pavement surface. A skid mark that was difficult to see was considered a faint mark. Over the surface area of a faint skid mark, the predominant visible color was that of the pavement surface. Most skid marks were considered average marks. The surface area of an average skid mark displayed a balance between the color of the pavement surface and the color of black tire rubber. For average skid marks, it was generally fairly easy to see the tire tread pattern on the pavement when viewing the video. A skid mark that appeared very black on the pavement was considered a dark mark. Over the surface area of a dark skid mark, the predominantly visible color was that of black tire rubber. For dark skid marks, the mark generally appeared to be a solid black line where tread marks could not be easily discerned.

Skip: the "skip" parameter indicates whether a skid mark appeared as a dotted line on the pavement. The individual dots of a skipping skid mark had to appear to follow the same trajectory (as if there were no dotted line at all) to be considered a single entity. Skipping was most likely to occur on marks that were also classified as heavy vehicles.

Thickness: the "thickness" parameter indicates the relative thickness of the skid mark. This parameter has no definitive parameters, but instead it indicates whether the mark got wider or narrower as the mark progressed longitudinally along the pavement.

\section{Data Availability}

The data used to support the findings of this study are available from the corresponding author upon request.

\section{Conflicts of Interest}

The authors declare that they have no conflicts of interest.

\section{References}

[1] A. Arun, M. M. Haque, A. Bhaskar, S. Washington, and T. Sayed, "A systematic mapping review of surrogate safety assessment using traffic conflict techniques," Accident Analysis and Prevention, vol. 153, pp. 1-20, 2021. 
[2] F. L. Mannering and C. R. Bhat, "Analytic methods in accident research: methodological frontier and future directions," Analytic Methods in Accident Research, vol. 1, pp. 1-22, 2014.

[3] T. K. Datta, D. D. Perkins, J. I. Taylor, and H. T. Thompson, Accident Surrogates for Use in Analyzing Highway Safety Hazards. Publication FHWA-RD-82-103, FHWA, U.S. Department of Transportation, Washington, DC, USA, 1982.

[4] A. Tarko, G. Davis, N. Saunier, T. Sayed, and S. Washington, "White paper: surrogate measures of safety," Committee on Safety Data Evaluation and Analysis (ANB20), 2009.

[5] K. F. Wu and P. P. Jovanis, "Crashes and crash-surrogate events: exploratory modeling with naturalistic driving data," Accident Analysis \& Prevention, vol. 45, pp. 507-516, 2012.

[6] H. Y. Gao and Z. Z. Tian, "Determination of crash surrogates using tire skid marks," in Proceedings of the Seventh International Conference onTraffic and Transportation Studies, pp. 1457-1468, ASCE, Kunming, China, August 2010.

[7] A. P. Tarko, "Use of crash surrogates and exceedance statistics to estimate road safety," Accident Analysis \& Prevention, vol. 45, pp. 230-240, 2012.

[8] S. Jaehyun and D. George, "Development and evaluation of an enhanced surrogate safety assessment framework," Transportation Research Part C, vol. 50, no. 50, pp. 51-67, 2015.

[9] K. Mattas, M. Makridis, G. Botzoris et al., "Fuzzy surrogate Safety Metrics for real-time assessment of rear-end collision risk. A study based on empirical observations," Accident Analysis and Prevention, vol. 148, pp. 1-10, 2020.

[10] D. Yang, K. Xie, K. Ozbay, and H. Yang, "Fusing crash data and surrogate safety measures for safety assessment: development of a structural equation model with conditional autoregressive spatial effect and random parameters," Accident Analysis and Prevention, vol. 152, pp. 1-13, 2021.

[11] N. Saunier and T. Sayed, "Probabilistic framework for automated analysis of exposure to road collisions," Transportation Research Record, vol. 2083, no. 1, pp. 96104, 2008.

[12] C. Oh, J. Oh, and J. Min, "Real-time detection of hazardous traffic events on freeways: methodology and prototypical implementation," Transportation Research Record, vol. 2129, no. 1, pp. 35-44, 2009.

[13] A. Laureshyn, A. Svensson, and C. Hydén, "Evaluation of traffic safety, based on micro-level behavioural data: theoretical framework and first implementation," Accident Analysis \& Prevention, vol. 42, no. 6, pp. 1637-1646, 2010.

[14] P. St-Aubin, N. Saunier, and L. Miranda-Moreno, "Largescale automated proactive road safety analysis using video data," Transportation Research Part C: Emerging Technologies, vol. 58, pp. 363-379, 2015.

[15] Y. Kuang, X. Qu, and S. Wang, "A tree-structured crash surrogate measure for freeways," Accident Analysis \& Prevention, vol. 77, pp. 137-148, 2015.

[16] K. Xie, C. Li, K. Ozbay et al., "Development of a comprehensive framework for video-based safety assessment," in Proceedings of the 2016 IEEE 19th International Conference on Intelligent Transportation Systems (ITSC), pp. 2638-2643, Janeiro, Brazil, November 2016.

[17] S. M. S. Mahmud, L. Ferreira, M. S. Hoque, and A. Tavassoli, "Using a surrogate safety approach to prioritize hazardous segments in a rural highway in a developing country," IATSS Research, vol. 44, no. 2, pp. 132-141, 2020.

[18] Y. Kuang, Y. Yu, and X. Qu, "Novel crash surrogate measure for freeways," Journal of Transportation Engineering, Part A: Systems, vol. 146, no. 8, p. 04020085, 2020.
[19] A. P. Tarko, "Surrogate measures of safety," in Safe Mobility: Challenges, Methodology and Solutions, pp. 383-405, Emerald Publishing Limited, Bingley, UK, 2018.

[20] L. Zheng, T. Sayed, and F. Mannering, "Modeling traffic conflicts for use in road safety analysis: a review of analytic methods and future directions," Analytic Methods Accident Research, vol. 29, Article ID 100142, 2020.

[21] D. J. Torbic, D. W. Harwood, D. K. Gilmore, and K. R. Richard, Interchange Safety Analysis Tool (ISAT): User Manual. Publication FHWA-HRT-07-045, FHWA, U.S. Department of Transportation, Washington, DC, USA, 2007. 